\title{
O PRINCÍPIO DA PRECAUÇÃO dever do Estado ou protecionismo disfarçado?
}

\author{
Sueli Gandolfi Dallari \\ Deisy de Freitas Lima Ventura
}

\begin{abstract}
Resumo: A inclusão da saúde pública na ordem do dia dos movimentos sociais, em especial a resistência ao processo de globalização, coincide com um impasse na evolução da liberalização do comércio mundial, diante da inexistência de consenso entre os Estados sobre a questão agrícola. O princípio da precaução surge nessa complexa equação como obstáculo ao livre-comércio ou pode ser interpretado como forma de mascarar o protecionismo que caracteriza os Estados desenvolvidos.

Palavras-chave: princípio da precaução; saúde pública; protecionismo.
\end{abstract}

Abstract: The inclusion of public health as an agenda item within grass-roots movements, especially the antiglobalization movement, coincides with an impasse in continued liberalization of world trade, due to a lack of consensus between nations with regard to agricultural issues. The precautionary principle emerges within this complex equation as an obstacle to free trade, or as an attempt to mask the protectionist tendencies of developing nations.

Key words: precautionary principle; public health; protectionism.

A

última década do século XX foi marcada por importante mudança nas bandeiras de luta dos movimentos sociais. A resistência organizada contra o processo histórico, que se convencionou chamar de "globalização", empunha novos estandartes e, entre eles, encontra-se o da saúde pública. Mais do que reivindicar a ação do Estado nessa área, tais movimentos exigem transparência no tratamento das questões sanitárias, sobretudo no que atine à cadeia alimentar, ou seja, o processo que vai da produção à comercialização dos alimentos. Além disso, questiona-se a legitimidade de acordos internacionais de comércio que privilegiam interesses econômicos em detrimento da segurança sanitária. Uma das figuras emblemáticas desse movimento é o militante francês José Bové, que em sua luta contra a malbouffe não hesita em destruir plantações transgênicas e atacar as franquias do McDonald's.

Parece claro que a bandeira da saúde chega ao público principalmente pelos escândalos que envolveram a cadeia alimentar nos últimos dez anos, com destaque para o caso da "vaca louca" (encefalopatia espongiforme bovina) que assolou a Europa, e da discussão acerca da comercialização de produtos alterados geneticamente, conhecidos como transgênicos.
É precisamente nesse momento de publicização inédita do debate da saúde que a liberalização do comércio mundial chega a seu grande impasse: o desmantelamento da proteção tarifária e não-tarifária no setor da agricultura. Os países desenvolvidos recusam-se a abrir seus mercados, protegendo sua produção e, ao menos no caso da Europa, preservando também sua qualidade de vida, por meio da multifuncionalidade da agricultura e do modelo intensivo de produção. Já os países em via de desenvolvimento lutam pelo acesso aos grandes mercados, e é por intermédio da inserção no comércio internacional que procuram a superação de seus graves problemas econômicos.

A opinião pública tende a situar-se, em um primeiro momento, dentro da "comunidade de destino" de que fala Edgar Morin, de modo que todos os humanos estão confrontados aos mesmos problemas de vida e de morte, que ultrapassam largo os limites de cada soberania, relativos precipuamente à sobrevivência da espécie (saúde) e do planeta (meio ambiente). Em outras palavras, existe o reconhecimento de que o Estado-Nação não teria, hoje, condições de lidar sozinho com as questões sanitárias e ambientais, devendo dirigir-se à integração, e não ao isolamento, para cumprir corretamente seu papel de proteção 
do indivíduo. Ainda é cedo para avaliar o peso político dessa “opinião pública internacional", dessa nova classe política, de indivíduos e grupos que tecem vínculos transnacionais, independentes do Estado, que Philippe Moreau Defarges chamou de "sociedade civil mundial". Contudo não há dúvidas de que ela tende a defender as causas da saúde e o ambiente como questões de princípio.

Em sentido contrário, quando ocorrem situações como a retaliação comercial imposta pelo Canadá ao Brasil que impediu recentemente a entrada em território canadense da carne brasileira, apresentada como suspeita, em aplicação do princípio da precaução -, a opinião pública tende a reagir de modo violento, em defesa do Brasil, tachando a atitude canadense de falso protecionismo. É evidente que, nesse caso, a aplicação do princípio mostrouse, na verdade, descabida. Questiona-se, porém, como reagirá a opinião quando estiver diretamente oposta, de um lado, a precaução legítima, assecuratória da saúde pública de outros povos e, de outro lado, um prejuízo econômico nacional de monta?

Esse panorama geral impele à tentativa de precisar o conceito de saúde pública e de discernir de modo claro o significado da polêmica noção de precaução no âmbito sanitário, aprofundando essas noções tão facilmente manipuláveis no discurso político, o que permitiria identificar alguns dilemas relativos à aplicação desse princípio no âmbito do comércio internacional. Assim, em um primeiro momento, será tratado o deslocamento do eixo da noção de saúde pública, que se consolida pela idéia de prevenção, mas ruma mais à frente para a precaução. A seguir, será dimensionado o princípio da precaução no contexto da moderna concepção de saúde. Finalmente, será possível refletir sobre esse novo elemento como dado político do complexo cenário internacional, em especial no âmbito dos blocos econômicos.

\section{DA PREVENÇÃO À PRECAUÇÃO: A EVOLUÇÃO DO CONCEITO DE SAÚDE PÚBLICA}

A evolução histórica mostra que o atual conceito de saúde pública começa a se delinear no Renascimento, correspondendo praticamente ao desenvolvimento do Estado Moderno. É muito curioso - porque absolutamente desprezado - verificar a aproximação histórica da idéia de saúde da de exercício físico (ginástica) e dieta, isso porque a saúde não é na origem um conceito científico, mas uma idéia comum, ao alcance de todos.
Para a antigüidade grega o termo hygieia significa "o estado daquele que está bem na vida" e tem um sentido eminentemente positivo. Mesmo com a incorporação do sentido de cura e, portanto, com a formação da medicina, ainda a higiene alimentar e o exercício físico são caracterizados como importantes elementos de cura. ${ }^{1}$ Platão (s.d.:444b-c) amplia, um pouco mais, a idéia de saúde, acrescentando-lhe o campo da alma e a necessidade de que ele mantenha relação adequada com o corpo. Assim, o estado de equilíbrio interno do homem com a organização social e a natureza é sinônimo de saúde para a antigüidade grega.

Durante a Idade Média o saber culto continua a privilegiar o equilíbrio na definição de saúde (Maimônides). Tratados de ginástica e dietética são publicados como receitas de saúde para os não-médicos (Rauch, 1995), mas a reação coletiva à epidemia é a imagem mais marcante desse período. Assim aparecem os primeiros contornos da idéia de prevenção, implicando o respeito seja aos signos do zodíaco, seja ao desenrolar das estações, seja ao relacionamento adequado entre o clima e o corpo humano, mas, sobretudo, o afastamento dos contactos impuros - a melhor forma de prevenção.

No Renascimento, um fato importante para a compreensão do conceito de saúde pública foi a preocupação das cidades em prestar cuidados aos doentes pobres em seus domicílios ou em hospitais, aumentando o poder das cidades em matéria de higiene. Novas concepções de saúde favorecem a limpeza e os exercícios corporais que evitam o recurso aos medicamentos (Montaigne, s.d.), enquanto outras tendem a mecanizar o corpo, trabalhando com um conjunto de fatores que constituem a saúde (eliminação dos resíduos, apetite, facilidade de digestão). E a valorização do exercício como elemento essencial para uma vida saudável encontra reforço no romantismo, que estimula maior aproximação da natureza. Entretanto, a experiência das epidemias deixou sua marca, elaborando o conceito de perigo social, "usado mais como pretexto para um controle sobre as pessoas e não somente sobre as doenças do que para medidas específicas de prevenção" (Berlinguer, 1988:82).

É nesse período que, na Alemanha, define-se a idéia de polícia médica, em plena coerência com o cameralismo. ${ }^{2}$ Não tendo os alemães participado ativamente das grandes navegações e da colonização decorrente, o principal objetivo do mercantilismo foi aumentar a força interna do Estado - particularmente depois que o império germânico foi esfacelado nos Tratados de Paz da Westphalia (1648) - 
para o que foi importante o conceito de polícia. Concordando com a ideologia hegemônica na Alemanha no final do século XVII, que afirmava ser o crescimento populacional a manifestação primeira da prosperidade e bem-estar de um povo e que, portanto, um bom governo deve agir para proteger a saúde de seus súditos, Leibnitz sugeriu, em 1680, ao imperador Leopoldo I, a criação de um órgão administrativo encarregado dos assuntos de polícia, o que implicava a existência de um conselho de saúde. Logo após (1685), Frederico-Guilherme de Hohenzollern - o Grande Eleitor de Brandemburgo - cria, nos territórios que viriam a constituir o reino da Prússia, um Collegium sanitatis, definindo uma autoridade médica para supervisionar a saúde pública (Rosen, 1980:151-53).

Nesse período pode-se observar, também, que o ensino do cameralismo na Universidade - iniciado sob o reinado do, então, imperador Frederico-Guilherme I - favorecendo o desenvolvimento do ramo da Administração Pública conhecido como ciência da polícia, forneceu as bases para a definição da polícia médica, ${ }^{3}$ a ele estruturalmente vinculada. Assim, a teoria política do contratualista barão de Pufendorf (1732:349) - revelada no Direito natural e direito das gentes, de 1672 - além de insistir que "a força de um Estado consiste no valor e nas riquezas dos Cidadãos: ... [e que o Soberano, portanto,] ... não deve nada negligenciar, para promover o cuidado e o aumento dos bens dos particulares", dedica no Capítulo VI, livro 2 aos "deveres do homem com relação a ele mesmo, tanto para o que respeita ao cuidado de sua alma, quanto para aquilo que concerne ao cuidado de seu corpo e de sua vida". Nesse trecho ele afirma ser necessário "trabalhar para ter a saúde com bom-senso" (Pufendorf, 1733:244), lembrando que a saúde encerra todos os outros bens. E seus seguidores, como von Justi, escrevendo no auge do despotismo esclarecido ${ }^{4}$ (exercido na Alemanha por Frederico II - 1740-1786), advogavam que o soberano fizesse todo o possível para prevenir as doenças contagiosas e para, em geral, diminuir as doenças entre os súditos. Para isso deveriam, empregando o aparato administrativo do Estado, estimular a prática da medicina, da cirurgia, do partejo, da farmácia e regulamentar o exercício dessas atividades para evitar abusos e charlatanismo. Deveriam, também, promover a pureza da água e dos alimentos, assim como, assegurar a higiene do meio, regulando, inclusive, as edificações em solo urbano (Rosen, 1980:159).

Fica claro que a sistematização da polícia médica resulta, em especial, da profunda influência exercida - du- rante todo o século XVIII - pela filosofia do Iluminismo, que considera a razão o único caminho para a sabedoria. Assim, ao não admitir as explicações sobrenaturais para os fenômenos naturais, o Iluminismo promove a ampla aceitação da obrigação do Estado de controlar o exercício das práticas médico-cirúrgicas e farmacêuticas, combatendo o charlatanismo. Do mesmo modo, por buscar empregar o método científico na descrição das doenças e na determinação dos tratamentos, essa filosofia eleva o exercício das ciências médicas (como das demais profissões liberais) a uma condição de dignidade inimaginável na Idade Média, o que justifica plenamente a regulamentação estatal do ensino médico. E, também, ao advogar a possibilidade de planejamento da atividade estatal somada à exaltação crescente dos direitos naturais do homem - que permitiu consagrar mais atenção aos infortúnios das classes mais pobres - o Iluminismo estimulou a drenagem de pântanos, a abertura de canais, favorecendo a prevenção de epidemias.

A noção contemporânea de saúde pública ganha maior nitidez de contorno no Estado liberal burguês do final do século XVIII. A assistência pública, que envolvia tanto a assistência social propriamente dita (fornecimento de alimentação e abrigo aos necessitados) como a assistência médica, continuou a ser considerada matéria dependente da solidariedade de vizinhança, na qual o Estado deveria envolver-se apenas se a ação das comunidades locais fosse insuficiente. Pode-se colocar nessa atuação subsidiária do Estado um primeiro germe do que viria a ser o serviço público de saúde. Entretanto, tomando-se o exemplo francês, verifica-se que a grande transição revolucionária que passa tanto pela supremacia dos jacobinos quanto pela militarização napoleônica - retarda o início da instauração efetiva da assistência à saúde como objeto do serviço público, para o período conhecido como Restauração. ${ }^{5}$

A proteção da saúde é admitida no elenco das atividades do Estado liberal e recebe, portanto, um status constitucional. Isso significa que, apesar do empirismo que caracteriza a regulamentação das atividades de interesse para a proteção da saúde, as medidas de polícia administrativa relativas à tal proteção devem estar sob o manto da lei. Apareceram, assim, durante a Restauração (para ficar no exemplo francês) as primeiras leis que tratavam organicamente da higiene urbana, da noção de estabelecimento insalubre e do controle sanitário de fronteiras (Forges, 1998:489-501). Não se pode ignorar, contudo, que, tanto o controle do ensino e do exercício da medicina e da farmácia - profissões cuja regulamentação estatal era 
advogada há cerca de 50 anos - quanto a manutenção dos hospitais pelas comunas, também, receberam acolhida constitucional, uma vez que o Estado liberal e burguês daquele final de século legislou sobre esses assuntos. ${ }^{6} \mathrm{Em}$ suma, as atividades do Estado relacionadas à vigilância sanitária, na implantação do liberalismo, eram em tudo coincidentes com os interesses da burguesia vitoriosa: valorizando sobremaneira o individualismo dominante, limitá-lo apenas no estritamente necessário à preservação da segurança individual, com o mais absoluto respeito à lei - condição do Estado de Direito.

Entretanto, é apenas na segunda metade do século XIX que a higiene torna-se um saber social, que envolve toda a sociedade e faz da saúde pública uma prioridade política. São desse momento as primeiras tentativas de ligar a saúde à economia, reforçando a utilidade do investimento em saúde. ${ }^{7}$ Inúmeros trabalhos de pesquisa conformes ao paradigma científico vigente revelam claramente a relação direta existente entre a saúde e as condições de vida. Assim, proteger a saúde das camadas mais pobres, modificar-lhes os hábitos de higiene, passa a ser um objetivo nacional, pois estar-se-ia pari passu, lutando contra a miséria que ameaça a ordem pública. A idéia de prevenção encontra, então, ambiente propício à sua propagação. De início, fomentada por associações, ${ }^{8}$ a prevenção transforma-se tanto em objetivo político quanto social. Tratava-se de encontrar os sinais precursores da doença para evitá-la. Nesse sentido, a vacinação - descoberta de Pasteur, com o posterior isolamento do germe - provoca uma verdadeira revolução na prevenção de moléstias, pois a proteção contra a infecção permite simplificar a precaução. São criados os Comitês de Vacinação e verifica-se que, politicamente, o risco de contrair doenças se sobrepõe ao da própria moléstia, transformando-a de episódio individual em objetivo coletivo, sobretudo por meio da disseminação dos meios estatísticos na avaliação da saúde.

No início do século XX encontra instaurada a proteção sanitária como política de governo. E são hierarquizadas três formas - hoje clássicas - de prevenção:" a primária, que se preocupa com a eliminação das causas e condições de aparecimento das doenças, agindo sobre o ambiente (segurança nas estradas, saneamento básico, por exemplo) ou sobre o comportamento individual (exercício e dieta, por exemplo); a secundária ou prevenção específica, que busca impedir o aparecimento de doença determinada, por meio da vacinação, dos controles de saúde, da despistagem; e a terciária, que visa limitar a pre- valência de incapacidades crônicas ou de recidivas (Leavell e Clark, 1976). O Estado do Bem-Estar social da segunda metade do século XX reforça a lógica econômica, especialmente em decorrência da evidente interdependência entre as condições de saúde e de trabalho, responsabilizando-se pela implementação da prevenção sanitária.

Instituem-se, então, os sistemas de previdência social, que não se limitam a cuidar dos doentes, mas organizam a prevenção sanitária. A princípio, pressupunham uma diferenciação entre assistência social - destinada às classes mais desfavorecidas e baseada no princípio de solidariedade e, portanto, financiada por fundos públicos estatais - e previdência social - mecanismo assecuratório restrito aos trabalhadores. Entretanto, exatamente porque a prevenção sanitária era um dos objetivos do desenvolvimento do Estado, logo se esclarece o conceito de seguridade social, que engloba os subsistemas de assistência, previdência e saúde públicas. ${ }^{10}$ Trata-se, portanto, de identificar a responsabilidade a priori do Estado. Assim, quanto aos estilos de vida, verifica-se um grande investimento estatal. ${ }^{11}$

Os últimos anos do século XX, contudo, revelam nova concepção da saúde pública, fortemente influenciada seja pelo relativo fracasso das políticas estatais de prevenção, que não conseguiram superar os limites impostos pela exclusão social, seja pela constatação - agora científica da importância decisiva de comportamentos individuais no estado de saúde.

Por outro lado, o predomínio da ideologia neoliberal provocou uma diminuição do papel do Estado na sociedade em favor dos grupos e associações e da própria responsabilidade individual. A evolução da organização dos cuidados relativos à Aids- na maioria dos Estados contemporâneos - é um exemplo eloqüente dessa nova concepção. Com efeito, prevaleceu a idéia de que a proteção contra a doença é responsabilidade individual e que os grupos - de doentes ou de portadores do vírus ou de familiares ou amigos deles - devem organizar a prestação dos cuidados de saúde, ficando o Estado subsidiariamente responsável pelo controle da qualidade do sangue, fator importante na cadeia da causalidade, mas, é claro, não o único. Reforça-se, assim, o papel dos comportamentos individuais e não se questionam as estruturas econômicas e sociais subjacentes. De fato, o que se verifica, então, é que as estruturas estatais de prevenção sanitária passam a estabelecer suas prioridades, não mais em virtude dos dados epidemiológicos, mas, sobretudo, em decorrência da análise econômica de custo/benefício. E isso, por ve- 
zes, acaba implicando a ausência de prevenção, elemento historicamente essencial ao conceito de saúde pública.

\section{NEM REMEDIAR, NEM PREVENIR: DESCARTAR OS RISCOS, O NOVO DESAFIO DO ESTADO}

No início do século XXI, a resposta inovadora que se busca construir para preservar o mundo de ameaças reais ou mesmo do sentimento geral de medo em relação à defesa da saúde pública, da qualidade dos alimentos e do equilíbrio do meio ambiente, chama-se "princípio de precaução". Curiosamente, tal anseio une segmentos sociais até então afastados por posições ideológicas, econômicas e culturais que pareciam inconciliáveis. Quer-se, ao mesmo tempo, preservar os benefícios resultantes do desenvolvimento científico e agir de modo que se garanta a precaução no domínio da saúde pública e do ambiente. ${ }^{12}$ Pode-se afirmar que a conviç̧ão de que todos os homens têm um destino comum, pois todos "estão no mesmo barco", tornou impossível a existência de riscos estritamente individuais.

Para avaliar o alcance da constatação de que o risco coletivo é de determinação cultural, recíproca e pública, basta lembrar que tal compreensão gerou a necessidade de uma nova teoria da justiça para dar forma política aos riscos sociais. Assim, apenas uma proteção eficaz contra as injustiças relativas à liberdade ou à igualdade pode garantir o sentido da justiça e o apego moral aos valores políticos, indispensáveis à ação após a descoberta do futuro comum (Worms, 1996:287-307).

O fenômeno social traduzido no princípio de precaução levou, igualmente, ao desenvolvimento de uma filosofia da precaução (Ewald, 1996:382-412), ${ }^{13}$ construída com base em uma história da prudência, que revela, a princípio, o domínio do paradigma da responsabilidade, substituído - na passagem para o século XX - pelo da solidariedade. É a segurança - o novo paradigma, em fase de formação - que dá às obrigações morais a forma de ética e transforma o princípio de responsabilidade em precaução. Com efeito, a idéia moderna de responsabilidade buscava tornar o homem prudente, pois sancionava o comportamento contrário àquele que deveria e poderia ser previsto. Definia-se a noção de culpa, que articulava a sanção, à prevenção e à indenização. A responsabilidade era, sem dúvida, um excelente princípio regulador, que perdia sua eficácia diante da dúvida ou da incerteza - elementos cada vez mais freqüentes na sociedade que se in- dustrializava - induzindo sua suplantação pelo princípio da solidariedade. Tratava-se, assim, de compensar o prejuízo decorrente dos acidentes que não se era capaz de prevenir. O motor principal dessa transformação foram os acidentes do trabalho e as aposentadorias. A responsabilidade permanecia em ação no que respeitava ao comportamento imprudente, mas a solidariedade garantia a indenização nos casos em que - embora se tenha tomado todas as precauções para evitá-los - os acidentes aconteciam.

A sociedade passou a organizar, então, as formas de repartir os riscos considerados eminentemente sociais, chamando de responsável aquele que ela considerava justo que suportasse o prejuízo pecuniário, fosse ele o autor ou a vítima. Esse foi o clímax do seguro social, que - também, sem dúvida - influiu para uma diminuição na atenção dada ao comportamento individual imprudente.

O desenvolvimento social revela que na base das sociedades securitárias do Estado de Bem-Estar, encontrava-se a crença numa ciência capaz de sempre melhor controlar os riscos. Ora, é exatamente a constatação de que a própria evolução científica vem aumentado os riscos imprevisíveis, que está provocando a afirmação do novo paradigma, o da segurança. Assim, num contexto de incertezas científicas e do risco da ocorrência de danos graves e irreversíveis, ele induz à formação do princípio de precaução. É igualmente evidente que esse princípio pretende conter a inovação, re-orientando o progresso científico ilimitado e re-valorizando a busca dos verdadeiros responsáveis pelos comportamentos imprudentes. Desse modo, o princípio de precaução não se compraz apenas com a caracterização do dano a ser compensado, pois ele abriga a convicção de que existem comportamentos que devem ser proibidos, sancionados e punidos. A mudança é, portanto, significativa: não basta determinar o montante da indenização, pois existem danos que não têm preço.

A teoria, que começa a ser construída, sobre o princípio de precaução procura minimizar o argumento de que ele conduza à abstenção e, portanto, à estagnação do desenvolvimento científico. Afirma-se que, muito ao contrário, seu emprego deve implicar o aumento do investimento em ciência e tecnologia, uma vez que, em situações de risco potencial desconhecido, ele exige que se busque a solução que permita agir com segurança, ou seja, que se transforme o risco potencial, seja em risco conhecido, seja - ao menos - em risco potencial fundado. Trata-se, pois, de fenômeno social que implica a radicalização da democracia: exige-se o direito de participar - possuindo todas as informações necessárias e indispensáveis - das gran- 
des decisões públicas ou privadas que possam afetar a segurança das pessoas.

A aplicação do princípio de precaução impõe uma obrigação de vigilância, tanto para preparar a decisão, quanto para acompanhar suas conseqüências. E, sobretudo, ela promove a responsabilidade política em seu grau mais elevado, uma vez que obriga a avaliação competente dos impactos econômicos e sociais decorrentes da decisão de agir ou se abster.

Talvez a maior contribuição trazida pelo princípio da precaução seja, contudo, duplamente jurídica. Com efeito, ao deixar claro que se trata de analisar um risco, isto é, a possibilidade de causar dano a alguém, ainda que sem culpa, a exigência de precaução obriga a considerar, seriamente, a instituição da perícia judicial, mas, também, extra-judicial. É conveniente observar que o risco está de forma direta ligado à técnica, não ao indivíduo que dela se vale. A complexidade dos saberes envolvidos na decisão de instituir a vacinação generalizada contra uma grave infecção viral de incidência crescente, ou de retirar do mercado um produto suspeito de causar infecção e morte, com base apenas em informações epidemiológicas ainda não comprovadas em laboratório, por exemplo, requer a participação de peritos que não devem ser responsáveis pela decisão, mas de quem se exige o domínio sobre sua área de especialidade e que deverão responder - social e juridicamente - pelas informações prestadas. E, em caso de se exigir a resposta judicial, o juiz deverá ser capaz de formar seu convencimento com base na apreciação de relatórios periciais que traduzam a complexidade da pesquisa científica em informações que sejam compreensíveis para todos os interessados.

Verifica-se, portanto, a necessidade de investimentos tanto na formação dos pesquisadores, que deverão dominar, também, as ciências sociais - na teoria e na prática para serem capazes de comunicar à sociedade os resultados de seus experimentos, quanto das pessoas em geral, que necessitam conhecer as bases do trabalho científico para poderem escolher o grau de risco ao qual consideram aceitável submeterem-se em nome do progresso.

Por outro lado, o reconhecimento judicial do princípio de precaução implica, igualmente, a indispensável atualização da filosofia do direito no que envolve a teoria da responsabilidade, pois, para ser identificado, o risco exige que seja afastada toda possibilidade de culpa do autor. De fato, a sociedade contemporânea tem sido colocada diante de um falso dilema quanto a tal princípio. Os governantes buscam explicar suas decisões contestadas por ausência de precau- ção com o argumento da fatalidade (ou da força maior, em termos jurídicos) e os governados, ainda quando têm seu prejuízo indenizado, procuram penalizar todos os responsáveis pelo crime de não terem agido com precaução. Ora, juridicamente a aplicação do princípio de precaução nada mais é do que a exigência do comportamento prudente como condição para excluir a responsabilidade por culpa, o que exige a identificação do elemento voluntário na caracterização do ato. Entretanto, a evolução da teoria da responsabilidade - como já se observou - tem sido no sentido contrário, generalizando-se a chamada responsabilidade objetiva ou responsabilidade sem culpa, sobretudo em relação às ações do Estado, o que permite, com maior facilidade, a obtenção de indenização, estimulando, por sua vez, a generalização do seguro. Deixando de analisar o comportamento que gerou o dano, desconhecendo, portanto, o homem (negligente ou imprudente) ou não verificando sua falta de conhecimento ou sua competência técnica insuficiente (imperícia) a responsabilidade por risco, todavia, não satisfaz o prejudicado que não mais aceita apenas ser indenizado, mas deseja a identificação do culpado. Tal comportamento social deve servir aos filósofos e teóricos do direito para lembrar que a responsabilidade situa-se entre a retribuição e a imputação, ou seja, ela envolve tanto a indenização quanto a procura da verdade. ${ }^{14}$

Para um profissional da saúde pública, a análise dos elementos que constituem o princípio de precaução traz à memória, portanto, os fundamentos de sua arte, pois agir em saúde pública significa conduzir uma ação política, que, por sua vez, obriga à prudência. Assim, qualquer sanitarista em face de uma decisão deverá certificar-se do melhor estado da arte envolvido, empregando o conhecimento epidemiológico, e analisar as repercussões socioeconômicas e culturais do problema.

Ora, o uso da epidemiologia como instrumento de trabalho do sanitarista não prescinde do estabelecimento de um adequado e eficaz sistema de vigilância e de alerta; do mesmo modo que a compreensão do ambiente socioeconômico e cultural exige a participação ativa das pessoas para que se possa estabelecer a correta relação custo/benefício, indispensável à tomada de decisão em política de saúde. Verifica-se, portanto, que o novo "princípio de precaução" atualiza a tradicional "saúde pública". Embora seja necessário e justo lembrar essa verdade, é importante reconhecer a capacidade política de que dispõe tal princípio, servindo mesmo para despertar os Estados para uma de suas missões essenciais e prioritárias: proteger e preservar a saúde pública. ${ }^{15}$ 


\section{DIMENSÃO TRANSNACIONAL DA SAÚDE PÚBLICA: RESPOSTAS REGIONAIS}

A evolução do conceito de saúde pública indica, primeiramente, a afirmação do princípio da precaução como um dever do Estado. Contudo, sua aplicação mostra-se bastante complexa quando se trata de tomar precauções em relação a um produto ou objeto proveniente do exterior, ou que será exportado. Com efeito, as relações comerciais internacionais encontram no princípio da precaução um novo e inquietante ingrediente. Após a sensível diminuição das tarifas alfandegárias, a definição dos parâmetros fitossanitários no âmbito da $\mathrm{OMC}$ e o enquadramento das barreiras técnicas, começam a surgir claros indícios de novas formas de restrições dos fluxos comerciais mediante adoção do princípio da precaução.

As reservas emitidas pela $\mathrm{OMC}$ e a falta de definição jurídica do princípio da precaução pela Corte Internacional de Justiça não significaram seu fenecimento. A opinião pública, sobretudo na Europa Ocidental, levou a União Européia e seus Estados-Membros a lançarem mão do princípio da precaução, ao vislumbrar um risco potencial para a saúde pública ou o meio ambiente.

No feixe de relações internacionais cada vez mais marcadas pelo componente econômico, a precaução apresenta características que dificultam sua abordagem na prática das relações entre os Estados. Além da imprecisão terminológica aguda, o tratamento multidisciplinar do tema é obrigatório, tornando o diálogo inevitável entre profissionais das áreas humanas, especialmente da política e do direito, e os das exatas. Esse diálogo nem sempre é fácil, o que levou alguns autores a perceber uma cientificização da política (Comissão Européia, 2000a).

Em segundo lugar, na seara internacional, o valor jurídico desse princípio é indeterminado, com alcance diferenciado conforme as ordens jurídicas em questão. Há uma aparente oposição ontológica ao princípio do livre-comércio e uma aparente função de instrumento do protecionismo de países desenvolvidos no domínio agrícola, que leva a diplomacia econômica a percebê-lo com maus olhos, com tendência a recusar-se a incluí-lo em sua pauta de discussões.

Paradoxalmente, ele também é empregado por países em via de desenvolvimento, como foi o recente bloqueio da circulação de carne bovina entre os países do Mercado Comum do Sul, Mercosul, em razão da existência de focos de febre aftosa no Rio Grande do Sul e no Uruguai. Embora se possa discutir a questão da aftosa no Mercosul como uma questão de prevenção, e não exatamente de pre- caução, o fato é que houve de forma nítida uma restrição de comércio com o intuito de afastar um risco. O problema é sensível, sobretudo no que se refere às negociações do Brasil e do Mercosul com a União Européia, em que a precaução mostra-se como obstáculo concreto e fundamentado juridicamente à exportação de produtos agrícolas.

Finalmente, o princípio da precaução tem desempenhado recentemente a função de eixo político justificador dos movimentos internacionais de oposição ao processo de globalização, fundadores de uma nova noção de solidariedade, que tem como elementos o direito à vida saudável $\mathrm{e}$ o imperativo de preservação do planeta. Está em curso uma descaracterização dos representantes dos governos nacionais nas negociações multilaterais como representantes do povo e de seus interesses (meio ambiente, saúde, consumo), gerando inédito questionamento da legitimidade dos Estados em sua ação internacional. Nota-se, ainda, um deslocamento dos parâmetros do senso comum da good governance dos critérios econômicos em direção de maiores exigências relativas à proteção da vida. Daí decorre uma influência crescente no comportamento do consumidor quanto aos produtos empiricamente considerados como suspeitos; na seara interna, mas com repercussões externas, trata-se de elemento provocador de uma nova concepção acerca da responsabilidade civil e penal dos agentes públicos.

Tais características dimensionam bem a importância da precaução na atualidade, mas são insuficientes para definila e delimitar nitidamente suas ramificações. O princípio da precaução foi utilizado pela primeira vez no direito ambiental alemão (Vorsorgeprinzip), na década de 70, (Boy, 1999:5 $)^{16}$ impondo às autoridades alemãs a obrigação de agir diante de uma ameaça de dano irreversível ao meio ambiente, mesmo que os conhecimentos científicos até então acumulados não confirmem tal risco. Dele decorre igualmente a obrigação de instaurar um sistema de pesquisa que permita detectar riscos para o ambiente, mas também para a saúde pública (Vaqué et alii, 1999:85). Além do direito alemão, são poucos, entretanto, os regulamentos nacionais que consagram o princípio com precisão.

De maneira geral, o escopo da precaução é ultrapassar a prevenção. Não seria mais preciso que um dano se produzisse, ou se mostrasse iminente, para que um gesto, visando evitar a produção ou a repetição desse dano, fosse legítimo. Invertendo essa lógica, a precaução baseia-se na experiência em matéria técnica e científica: as vantagens que surgem a curto prazo são, com freqüência, seguidas de desvantagens a médio e longo prazo. Logo, é preciso 
dotar-se dos meios de prever o surgimento de eventuais danos, antes mesmo da certeza da existência de um risco.

Dimensionando tal princípio no quadro das relações comerciais internacionais, tem-se, grosso modo, que a incerteza científica autorizaria a restrição do comércio.

Paradoxalmente, os acordos regionais de integração econômica multiplicam-se, mas a maioria deles exclui a agricultura, considerado um tema sensível, e silencia a respeito do princípio da precaução. Tal situação não pode, entretanto, perdurar sem criar problemas insuperáveis a longo prazo.

Na Declaração de Quebec, da Cúpula das Américas 2001, quanto à gestão dos recursos naturais, os Estados Partes da futura Área de Livre Comércio das Américas (Alca) reconhecem que a proteção do meio ambiente e uso sustentável dos recursos naturais são essenciais para a prosperidade e para a sustentabilidade da economia, assim como para a qualidade de vida e a saúde das gerações presentes e futuras. A Cúpula compromete-se a implementar acordos ambientais multilaterais (AAMS) e a respeitar a Declaração do Rio de Janeiro, de 1992. Essa Declaração consagra o princípio da precaução. Entretanto, diferentemente da União Européia, países da Alca são intransigentes na defesa de que cada país tenha a autonomia para definir seus próprios níveis de proteção ambiental.

Após o caso da carne com hormônios que envolveu os Estados Unidos e a Europa, é de supor que aquele país lidere a recusa do princípio da precaução como elemento justificador da restrição do princípio do livre-comércio. É de se investigar qual a posição que será adotada pelas demais nações americanas e prescrutar se o princípio da precaução será ou não um desafio nessas negociações ou um ponto de união entre os países da futura Alca, tendo a clareza de que tal posição configuraria um pólo de atrito com outros Estados que defendem a consolidação do princípio da precaução como possível elemento restritivo do comércio internacional.

No âmbito do sistema de solução de controvérsias (ORD) da Organização Mundial do Comércio (OMC), em que $40 \%$ das controvérsias examinadas desde a criação do GATT referem-se à agricultura, o princípio da precaução é refutado claramente.

Três casos foram apreciados até o momento pelo ORD: o caso da carne bovina com hormônios, produzida nos Estados Unidos, cuja circulação foi proibida nos países da União Européia; o caso do salmão canadense, submetido pela Austrália a severas medidas preventivas; as fru- tas produzidas nos Estados Unidos, cuja entrada no Japão foi proibida, salvo quando os exportadores pudessem atestar a ausência de insetos devoradores.

O ORD considerou que o princípio da precaução não encontrou ainda uma formulação respeitável e que seria imprudente tomar partido contra ou a favor de sua aplicação. O ORD aproxima-se, assim, da posição dos Estados Unidos e do Canadá, para quem o princípio da precaução não faz parte do direito internacional público e constitui não mais do que uma orientação para os poderes públicos (Noiville, 2000:268).

A União Européia constitui o laboratório mais rico da aplicação do princípio da precaução no âmbito da segurança sanitária. A experiência da Europa é também significativa por tratar-se do maior importador/exportador mundial de produtos alimentares, que realiza trocas comerciais com todos os países.

No direito comunitário, o princípio da precaução estava, de início, limitado ao direito do meio ambiente, consagrado pelo artigo 174-2 do Tratado de Amsterdã. Contudo, tal postulado alargou-se progressivamente ao domínio da saúde e consolidou-se como verdadeira norma jurídica européia, incorporada, também, às regras sobre alimentação. ${ }^{17}$

Concretamente, a consagração desse princípio impõe aos Estados-Membros da União Européia e à Comissão Européia a obrigação de não aguardar a confirmação de um risco em matéria de saúde pública para agir. Um alimento cuja segurança é, apenas, duvidosa pode ser retirado do mercado, ter sua circulação proibida, ou ainda ser submetido a uma avaliação preliminar para que possa entrar ou permanecer no mercado. Todas essas medidas implicam, é óbvio, efeitos restritivos sobre o comércio.

A Europa vai adiante: o Livro Branco sobre a segurança dos alimentos determina que "A proteção da saúde pública não se limita à segurança química, biológica e física dos alimentos. Deve igualmente ter por objetivo assegurar a ingestão dos nutrientes essenciais, limitando a ingestão de outros elementos a fim de evitar efeitos negativos para a saúde, incluindo efeitos antinutricionais" (Comissão Européia 2000b). Por essa razão, a Comissão Européia apresentou propostas de Diretivas (normas européias que necessitam transposição nas ordens jurídicas nacionais) sobre alimentos dietéticos, complementos alimentares e alimentos enriquecidos. A Comissão pretende, ainda, apresentar uma "política nutricional" conforme Recomendações ao Conselho da União Européia relativas a orientações em matéria de regime alimentar. 
A posição sustentada pela Europa não encontra, porém, amparo no direito do comércio internacional, cuja preocupação primeira é evitar que a aplicação de medidas relacionadas à segurança alimentar sirva como camuflagem ao protecionismo comercial. Com efeito, o Acordo sobre a Aplicação de Medidas Sanitárias e Fitossanitárias (SPS), assinado no âmbito da Organização Mundial do Comércio, determina que o Estado, cujas regras são mais severas do que as normas internacionais em vigor, deverá justificar a manutenção ou a implementação de suas normas pelas provas científicas disponiveis (Bureau e Bureau, 1999:30). Assim, a justificação científica impõe-se como a espinha dorsal do texto (Maruyama, p.651).

Como já foi mencionado, os Estados que defendem o princípio da precaução argumentam, porém, que sua aplicação não supõe menos ciência mas, ao contrário, mais pesquisa científica. Tal estratégia compreende certas práticas dos governantes como: não contentar-se com pesquisas científicas sumárias, multiplicar perícias e controles, além de cercar-se do máximo possível de pareceres antes de permitir a circulação de um produto cuja segurança é discutível.

Desse modo, a precaução não seria reduzida apenas à gestão de uma crise ou urgência, mas como utensílio de acompanhamento da evolução tecnológica: avaliar os produtos antes de sua comercialização, seguir seus efeitos, constituir uma espécie de jurisprudência científica e, enfim, refletir e compreender de modo progressivo os efeitos de novos modos de produção (Hermitte e Noiville, 1993:391).

Para o direito ambiental, o princípio da precaução significa que os Estados devem tomar medidas para prevenir a degradação ambiental, mesmo na ausência de certeza científica absoluta quanto aos efeitos nefastos das atividades projetadas sobre o meio ambiente (Martin-Bidou, 1999:633). Ele compreende, assim, as questões nucleares, da camada de ozônio e dos fundos marinhos, mas igualmente o problema dos transgênicos e da biotecnologia de modo geral.

Se no direito da União Européia a aplicação do princípio da precaução em matéria ambiental é pacífica, seu valor jurídico resta, porém, vago na seara internacional. Isto se deve à imprecisão das convenções internacionais a ele relacionadas, assim como à recusa de parte de certas instâncias jurisdicionais a pronunciar-se sobre tais questões. Por tudo isso, apesar de sua consagração em diversos tratados internacionais e regulamentações nacionais, muitos autores lançam dúvidas sobre seu caráter normativo no âmbito do direito ambiental, preferindo reconhecer-lhe o estatuto de objetivo de caráter geral (Vaqué et alii, 1999:83).

No caso do Brasil, a questão da aplicação do princípio da precaução é paulatinamente afirmada pela ordem interna, orientada pelo art. 225 da Constituição Federal e outras normas, como a Lei n. 6.938/81, que trata da política nacional do meio ambiente, a Lei n. 7.437/85, que cuida da Ação Civil Pública, e a Lei n. 9.605/98, que zela pela proteção penal. ${ }^{18}$ Daí decorre uma possível interrogação sobre a responsabilidade penal e civil dos infratores das normas de proteção ao meio ambiente, tanto de governados como de governantes.

O Poder Judiciário brasileiro já foi provocado a manifestar-se sobre o princípio da precaução (Justiça Federal, 1999). Nas decisões judiciais é patente a confusão entre os princípios jurídicos da prevenção e da precaução, o que não impediu a determinação judicial da suspensão do cultivo, em escala comercial, da soja round up ready no Brasil, assim como da comercialização de sementes de soja geneticamente modificadas no território nacional. ${ }^{19}$

De maneira geral, os produtos geneticamente modificados têm provocado um fascinante contencioso, tanto no que atine à proteção da saúde como do meio ambiente. A tradução do princípio da precaução em verdadeira "ação de precaução" depende da evolução dos atuais sistemas de definição e de gestão de riscos. A dificuldade da aplicação do princípio consiste em dar uma resposta proporcional a um risco incerto, pois a precaução não existe por ela mesma: ela se constrói a cada contexto (Boy, 1999:333-51).

No atual estágio de conhecimento do tema, é natural que a União e os Estados brasileiros, na gestão da coisa pública, hesitem quanto à aplicação desse princípio. Essas hesitações, tanto aqui como nos demais países confrontados a essa situação, merecem ser relativizadas conforme o grau de precisão das obrigações que esse princípio engendra. Uma concepção mais restritiva do princípio facilitaria, aparentemente, a adesão das autoridades estatais, enquanto uma acepção mais ampla afastaria possíveis adeptos. Assim, a posição majoritária da doutrina e da jurisprudência é que esse princípio deve avançar, na seara ambiental, em direção de uma maior precisão: é a falta de clareza das obrigações nele implicadas que leva alguns a pôr em dúvida seu caráter normativo (Martin-Bidou, 1999:663-64).

Retomando o contexto comercial internacional, a questão agrícola apresenta-se como um dos maiores desafios 
das negociações entre o Mercado Comum do Sul, Mercosul e a União Européia. Após um longo período no qual as relações entre a Europa integrada e a América Latina se passavam no quadro da política comunitária de cooperação ao desenvolvimento, o final dos anos 80 e sobretudo a década de 90 trazem uma grande mudança na concepção das relações exteriores da hoje União Européia. O relacionamento intra-regional passa a compreender a cooperação política e a econômica, e o território da América Latina é coberto por acordos classificados de terceira geração, que compreendem, entre outros itens, a preparação de uma futura liberalização comercial.

Nesse contexto, destaca-se o acordo de cooperação inter-regional assinado entre a Comunidade Européia e o Mercosul, em Madri, em 1995, e a polêmica que o sucedeu no seio das instituições européias, referente à assinatura de um posterior acordo de associação entre os dois blocos econômicos. Nesse processo, ficou claro que o grande obstáculo à liberalização comercial entre as regiões é a questão da agricultura. De um lado, uma política agrícola comum que agoniza diante dos sucessivos escândalos que abalaram a produção européia e da própria insustentabilidade do modelo adotado no bojo da liberalização comercial mundial. De outro lado, um conjunto de países cuja produção tem dificuldades de afirmar sua segurança e confiabilidade em escala mundial, também afligidos por um modelo de produção ultrapassado, e internamente considerado como gerador de desigualdades sociais, merecendo políticas e investimentos de porte em seara interna.

Envolvidos num esforço de negociação significativo, Mercosul e União Européia adotam posições distantes, senão antagônicas, nas instâncias internacionais que discutem questões relativas à saúde e ao ambiente. Além disso, em caso de contencioso direto, o princípio da precaução encontra suficiente amparo jurídico para justificar importantes medidas restritivas de comércio em território europeu. Adicione-se a percepção dos países do Mercosul de que o princípio da precaução constitui pouco mais do que uma forma de protecionismo mascarado em discurso politicamente correto. Embora recentemente a Europa tenha feito um gesto importante em direção ao Mercosul, apresentando uma pauta concreta para a negociação e um nítido compromisso com a consolidação do bloco platino, nada indica que a divergência profunda relativa à questão agrícola tenha-se atenuado.

Esse artigo pretendeu suscitar o urgente debate sobre a saúde pública no âmbito do comércio internacional, colo- cando sobre a balança dos processos decisórios não somente os elementos econômicos, mas também a questão humana em toda a sua complexidade. O princípio da precaução desafia o direito do comércio internacional a criar regras que descartem o protecionismo mascarado, mas que permitam a exceção legítima. Ou seja, que possa ser desrespeitado o acordo de comércio sobre objeto que gere incerteza em termos de saúde humana, por razões claras e num processo decisório transparente, por maior ganho que a circulação de um novo produto possa representar. $\mathrm{O}$ problema é que, como bem sintetizou Mireille DelmasMarty (1999:209-16), não se queira procurar a palavra humanidade nos manuais de direito: no campo jurídico, a humanidade é realmente um recém-nascido.

Como um balanço das inquietações aqui expressas, lembre-se, com Edgar Morin, que toda a ação empreendida em meio à incerteza traz à tona a contradição entre o princípio do risco e o princípio da precaução, um tão necessário quanto o outro. Ficam as palavras de Péricles: "Nós sabemos dar provas de uma audácia extrema e, ao mesmo tempo, nada fazer sem antes uma profunda reflexão. Nos outros, a bravura é resultado da ignorância enquanto a reflexão engendra a indecisão"(Tucídides, Guerra do Peloponeso).

\section{NOTAS}

1. A medicina hipocrática é formada pela dietética ou ciência dos regimes e pela ginástica ou ciência dos exercícios.

2. Ensinam os historiadores da civilização que o mercantilismo alemão, interessado sobretudo em aumentar as rendas do Estado, ficou conhecido como "cameralismo", uma vez que Kammer significa tesouro real.

3. Sobre o tema ver, especialmente, Small, 1909.

4. Suas obras sobre a administração do Estado e os fundamentos da ciência da polícia datam de 1755 e 1756 , respectivamente.

5. 1814 (Primeira queda de Napoleão); 1830 (revolução de julho, queda de Charles X).

6. Na França, leis de 10 de março (medicina) e 11 de abril (farmácia) de 1803 e a lei de 16 vendémiaire na $\mathrm{V}$, que introduz um modelo de gestão comunal -, os diversos estabelecimentos e casas de caridade são reagrupados sob um estabelecimento público comunal, dirigido por uma comissão administrativa municipal, destinado, exclusivamente aos doentes locais.

7. Veja-se, por exemplo, os trabalhos de Chadwick, E. Rapport sur la condition sanitaire dês travailleurs en Grande-Bretagne; de Marshal, A. Príncipes d'economie politique; ou de Thünen, J.H.von L'etat isolé.

8. Tomando o exemplo francês, basta lembrar a Société française de tempérance, organizada em 1873, para atuar contra o alcoolismo; a Société protectrice de l'enfance, organizada em 1865, militando pela alimentação com leite materno; ou o Comitê de défense contre la tuberculose, criado em 1896. 
9. Veja-se, especialmente, a obra de Leavell e Clark (1976).

10. Modelo adotado, por exemplo, na Constituição Federal brasileira de 1988 (art.195).

11. Considere-se, por exemplo, os investimentos dos Estados contemporâneos na luta antitabagista.

12. Com esse objetivo o Primeiro Ministro francês encomendou aos professores Geneviève Viney e Philippe Kourilsky um estudo para definir a posição da França no quadro das discussões sobre a aplicação do princípio de precaução no seio da Organização Mundial do Comércio.

13. François Ewald, um dos mais respeitados autores da teoria do risco, vem trabalhando no tema nos últimos anos.

14. Veja-se a esse respeito a excelente obra de Morelle (1996), especialmente o capítulo dedicado à responsabilidade.

15. Tal é a integra de uma recomendação, para ficar no exemplo francês, do estudo citado: "Um esforço particular deverá ser feito em favor do ensino da saúde pública (que deverá imperativamente ser praticado nas escolas especializadas e não apenas nas faculdades de Medicina) e de todas as medidas permitindo desenvolver na França uma verdadeira cultura de saúde pública" (Kourisky e Viney, 2000:221).

16. No mesmo período, os legisladores norte-americanos introduziram esse princípio de maneira informal na maior parte das leis relativas ao meio ambiente.

17. Para análise completa do emprego do princípio da precaução na Europa, ver Comissão Européia.

18. Para um estudo preliminar, ver Paulo Affonso Leme Machado, "Direito ambiental e princípio da precaução", <www.merconet.com.br/ direito/1direito.htm>.

19. "Em certos casos, face à incerteza científica, a relação de causalidade é presumida com o objetivo de evitar a ocorrência de dano. Então, uma aplicação estrita do princípio da precaução inverte o ônus normal da prova e impõe ao autor potencial provar, com anterioridade, que sua ação não causará danos ao meio ambiente" (Justiça Federal, 1999:40).

\section{REFERÊNCIAS BIBLIOGRÁFICAS}

BERLINGUER, G. A doença. São Paulo, Cebes-Hucitec, 1988.

BOY, L. "La nature juridique du principe de précaution”. Nature Sciences Société, 1999.

. "Les organismes genetiquement modifiés entre le principe de précaution et l'ordre scientifico-concurrentiel (l'exemple des plantes transgéniques)". In: Philosophie du droit et droit économique: quel dialogue? Paris, Frison-Roche, 1999.

BUREAU, D. e BUREAU, J.-C. Agriculture et négociations commerciales, La Documentation Française. Paris, 1999, p.30.

COMISSÃO EUROPÉIA. COM (1999). Bruxelas, 12 jan. 2000c.

COMISSÃO EUROPÉIA. The future of parliamentary democracy: transition and chalenge in european governance. Green Paper, set. 2000c.

.Communication de la comission sur le recours au principe de précaution, COM, 1, 2000b, <http://europa.eu.int/comm/off/ com/health consumer/precaution.htm $>$.
DELMAS-MARTY, M. “Acession à l'humanité en termes juridiques”. In: Relier les connaissances. Paris, Seuil, 1999.

EWALD, F. "Philosophie de la précaution". L'Année Sociologique, v.46, 1996(2), p.382-412.

FORGES, J.-M.L. de. L'intervention de l'Etat en matière sanitaire: quelques repères historiques. Paris, Rapport Public, 1998 do Conceil d'Etat (La Documentation Française).

HERMitTE, M.-A. e NOIVILLE, C. "La dissémination dans l'environnement d'organismes genetiquement modifiés". Revue juridique de l'environnement, n.3, 1993.

JUSTIÇA FEDERAL, Seção Judiciária do Distrito Federal, Ação Cautelar Inominada, Idec com União Federal e outros, Processo 1998:34:00:0276818, sentença de 18/08/1999.

KOURISKY, P.; VINEY, G. Le principe de précaution. Paris, Odile Jacob, 2000.

LEAVELL; CLARK. Medicina preventiva. São Paulo, McGraw-Hill do Brasil, 1976.

MARTIN-BIDOU, P. "Environnement et principe de précaution". Revue Générale de Droit International Public, n.3, 1999.

MARUYAMA, W.-H. "A new pilar of WTO: sound science". The International Lawyer, v.32, n.3, s.d., p.651.

MONTAIGNE, M. de. Essais, II, 37; II, 2.

MORELlE, A. La défaite de la santé publique. Paris, Flammarion, 1996.

NOIVILLE, C. "Principe de précaution et OMC - Le cas du commerce alimentaire”. Journal de Droit International, v.2, 2000, p.268.

PLATÃO. A república, IV, 444b-c.

PUFENDORF, S. Le droit de la nature et des gens. Livro 6, Capítulo IX. Traduzido por Jean Barbeyrac, $4^{\mathrm{a}} \mathrm{ed}$. BÂLE, E. e THOURNEISEN, J.R. frères, 1732, tomo 2.

RAUCH, A. Histoire de la santé. Paris, PUF, 1995.

ROSEN, G. Da polícia médica à medicina social. Rio de Janeiro, Graal, 1980

SMALL, A.W. The cameralists: the pioneers of German social polity. Chicago, University of Chicago Press, 1909.

VAQUÉ, L.G.; EHRING, L.; JACQUET, C. "Le principe de précaution dans la législation communautaire et nationale relative à la protection de la santé”. Revue du Marché Unique Européen, 1999.

WORMS, F. "Risques communs, protection publique et sentiment de justice”. L’Année Sociologique, v.46, 1996(2), p.287-307.

Sueli Gandolfi Dallari: Professora da Faculdade de Saúde Pública da Universidade de São Paulo.

Deisy de Freitas Lima Ventura: Professora do Curso de Direito e do Mestrado em Integração Latino-Americana da Universidade Federal de Santa Maria; DEA Direito Comunitário e Europeu da Universidade de Paris I. 